\title{
The Role of Employee Engagement in Anticipating Counterproductive Work Behavior: A Study of Literature
}

\author{
Prof. Dr. Yupono Bagyo, SE., MS., MM., CHRP \\ Professor in Human Resource Management, College of Economics Malangkucecwara, Malang, Indonesia
}

\begin{abstract}
Employee engagement is getting more realized to be an important issue of human resource management and development in improving performance. It is also felt to be effective in anticipating the harmful behaviors performed by employees commonly called counterproductive works behaviors (CWB). The danger of CWB must threaten the sustainability, the future prospect, and the reputation of an organization because it does not only harm the organization, but also the members and the customers. Employee engagement is promising, CWB is frightening and damaging. Engaged employees will be safe from CWB which in turn bring fort an organization stronger to any changes and challenges, and at the same time proactively create and/or responsively take a great opportunity to accomplish the goal of an organization. This study is aimed at exploring definitions of the two concepts, analyzing the drivers of employee engagement and the dimensions of $C W B$, and detailing the roles of employee engagement in anticipating CWB. It is identified that employee engagement plays very important roles in anticipating $C W B$, such as 1) as the effective strategy in improving performance, 2) as the effective way to increase work outcome and/or business outcome, and 3) in the frame of future prospect of organization, as the key tool of success of an organization. The three facets of improvement are only achieved with highly-engaged employees who are surely kept away from CWB.
\end{abstract}

Keywords: employee engagement, counterproductive work behavior (CWB), engaged employees, performance.

\section{Introduction}

Future is uncertain. This word is more realized through the time of change because of the weaknesses of human being as one of God's creatures. Every one cannot ensure what the future looks like of the organization and others of lives. The uncertainty implies that any great efforts are required and must be prepared and performed to anticipate and create a good sound of organizational life in the future. One of the most important things to do is fostering the employees' capabilities and skills, and the maintenance as well. The three facets of effort is unified which in turn is able to bring fort engaged employees. The employee engagement has recently been discussed as an interesting focus in managing and developing human resource.

Employee engagement may be understood as an emotional condition and a behavioral action to a given work environment in an organization (Khan, 2009; Robinson, 2005; Hewitt Associate, 2004). The former aspect of an emotional condition, engagement refers to ideas like focus, motivation and passion for the task at hand. While the latter aspect of a behavioral reaction, engagement goes beyond the employees' feelings and attitudes. Engaged employees can provide significantly much more discretionary effort by doing whatever considerably useful to finish any work tasks for the organization. Whatever they do brings a positive outcome on business results. In fine that engaged employees 'say' good things on working at the organization, they like to 'stay' at the organization and they 'strive' to give extra and discretionary efforts which are beneficial for the organization (Hewitt Associate, 2004, as cited by Ahlowalia et al, 2014).

Doing more for something more and giving more for more usefulness are philosophical mind to be realized in an organizational life. Engaged employees must have such philosophical mind-set in performing their work tasks for the better and extra benefits for the organization. Whatever is done on the line to the mission, vision, and objectives clearly stated by the organization. They have a strong personal involvement in the organization in any cases, and a strong character in striving and struggling for the improvement from time to time. They enjoy doing more and extra efforts considerably useful for the organization and the members. Such employees certainly give a very good future prospect and reputation to the organization.

Based on the thought stated above, employee engagement which has already been set up should be maintained by the organization. If not, they potentially suffer from counterproductive diseases that will harm the organizations and the members. Such diseases can be in the form of harmful behavior which is commonly called counterproductive work behaviors (CWB). It is also called in many ways by researchers, such as organization attack (Baron \& Neuman, 1996; Neuman \& Baron, 1997; Spector, 1975), audacious behavior (Andersson \& Pearson, 1999), anti-social behavior (Giacalone \& Greenberg, 1997), workplace deviant behaviors (Hollinger, 1986; Robinson \& Bennett, 1995) and vindictive act (Skarlicki \& Folger, 1997). The various terms comes to one thought that CWB is a deviant behavior which is harmful for the organization and the members, and the customers as well. 
Such behavior is certainly causes high economic costs for the organizations, psychological, and social costs as well (An, Feng \& Wang, Bing (2016). That is why, it should be well-controlled or the organizations go to a great lost. Many researchers call $\mathrm{CWB}$ as a cancer threatening the life of organizations. It surely breaks or disrupts great organizational values, leading to intimidate the welfare and the future of an organization and its members. CWB also brings fort communication gaps among managers, between employees and the management, makes employee morale and commitment lower. Then, CWB is commonly perceived as the negative and opposite of employee engagement.

In fact, no organizations are free from CWB. All of them have with different level of intensity and capacity. It is due to the dynamic aspect of human and the environment. The organizations are required to keep them from harmful deviants performed by the employees and at the same occasion to keep them engaged any way. Managing employee engagement especially during the time of change is not easy work. Some integrated approaches and strategies should be contextually applied under total efforts aligning to the mission, vision, and objectives of the organization. The concept of commitment in management is said to be a foundation in building employee engagement. It is impossible for the organization to get engaged employees without a strongly built commitment within the organization.

A good organization today, during the time of change, is organization whose great employees who are not only committed but engaged. Those who are said to be committed if they perform on the required level of outcomes, meet the individual and organizational goals by performing required efforts within the organization. As engaged employees, they perform very well beyond the required level of outcomes along with the increasing of their proficiency, capabilities and skills. They sincerely do the tasks without any pressure and intentionally and personally struggle for the great usefulness within the organization. The engaged employees really enjoy accomplishing any work tasks, including helping others and sharing ideas for better and improvement. They are not only helpful but also open-minded in solving any problems of others and have a quite strong involvement and feeling in pursuing the organizational objectives.

Concerning with CWB, commonly known as the opposite of employee engagement, researchers come to one thought that it is rising when the drivers of CWB are exhibited within the organization such as organizational injustice, frustrating working condition, work stress, job dissatisfaction, abusive supervision, lack of organizational supports. The rising of CWB is also said to be a response and/or a protest done by the employees, even the engaged employees for the human resource practices which is considerably deviant. The engaged employees may take turn into CWB area due to the unsound human resource practices or the dysfunctional leadership within the organization.

This article discusses the two concepts: employee engagement and CWB based on today issues of literature with some limitations. Firstly, it explores the definitions of each. Secondly, it discusses the potential factors driving employee engagement. Thirdly, it discusses the dimensions of CWB potentially harm the organization and its members. Fourthly, it details the roles of employee engagement in anticipating and saving employees from CWB. Finally, this article recommends something to do considerably useful for the organization to make employees engaged and keep them away from CWB and further research to conduct related with employee engagement improvement and CWB avoidance.

\section{Method}

This study is systematically done on the base of literature overview on employee engagement and counterproductive work behavior. The literature overview is conducted to synthesize the researchers' thought and evidence concerning the definitions or the two concepts, the drivers of employee engagement, the dimensions of CWB, and the roles of employee engagement in anticipating CWB. Based the finding of this study, the conclusion and the recommendation are presented. The literature needed in this study is primarily sourced from internet and human resource management journal databases, such as Elsevier, Emerald, etc.

\subsection{Definition}

\section{Employee Engagement}

In today era, employee engagement has been a central of interest in the study of human resources development and management. Along with advanced technology and streamlined work processes the discretionary efforts exhibited by the engaged employees are needed to foster efficiency and effectiveness which in turn improve quality, productivity, and business results as well. Then, it invites many researchers and experts to define for the real understanding of the concept. Many definitions of employee engagement formulated in various forms and thought, but essentially refer to one real meaning, the discretionary and extra efforts performed by the employees.

Khan (1990) is the first and most popular scholar, in the academic literature, who defines employee engagement as "the harnessing of organization members' selves to their work roles; in engagement, people employ and express themselves physically, cognitively, and emotionally during roles performances". Three 
The Role of Employee Engagement in Anticipating Counterproductive Work Behavior: A Study of..

aspects becomes the point in definition that is exerted by the employees under the discretion within an extra effort for the organization. The physical aspect is related to the physico-motoric action exerted by the employees to accomplish the goal. The cognitive aspect concerns with their beliefs and perception on the organization, the management, and the working condition and environment. The emotional aspect refers to their feeling on each of the three aspects and their attitudes to the organization and the management. In fact, according to Khan (1990), an employee may be engaged on one of the dimensions and they may not on the others. Therefore, they should be driven to be more engaged on each dimension to reach an overall higher level of engagement.

Hewitt Associate (2004) presents a definition of employee engagement as "the state in which the individuals are emotionally and intellectually committed to the organization or the group." The engaged employees, according to Hewitt Associate (2004) perform 3S: Say (they speak positively any way about the organization to other people inside and outside the organization), Stay (they have great intense to be a good member of the organization), and Strive (they perform much more effort and keep engaging in behavior useful for the success of the organization). This definition contains a resemblance point with Khan's definition in the case of the emotional and the intellectual. The physical aspect as stated by Khan is not considered to be discussed by Hewitt Associate. In fine, the commitment which is emotionally and intellectually performed by the employees is called employee engagement. The most interesting presented by Hewitt Associate related with employee engagement is the model of employee engagement telling about the factors affecting employee engagement level.

Howard and Foster (2009) as cited by Kaliannan \& Adjovu (2014) define employee engagement as "a critical tool in talent management that does not only fortify the competitiveness of the firm, but also enhance the organizational image because it helps to reduce employee attrition rate in business firm." This definition focuses on employee engagement as an instrument of organization to increase organizational competitive advantage level and reputation. As a tool of organization, employee engagement is perceived to be able to create a talent management in which the unique capability and skill the employee owns are developed and in such condition engaged employees are expected to be highly-valued assets for the organization. Referring to this definition, Kaliannan \& Adjovu (2014) also define employee engagement as an "engine" operated in talent management whose heavy duty and big power of resilience driving effectiveness and efficiency in any environmental condition and time of change within and outside the organization. The two definitions says clear understanding about the position of employee engagement in talent management showing that management is said to be talent management if it has overall engaged employees.

The definition of employee engagement is also formulated by another scholar, such as Schaufeli et al (2002) defining engagement as "a positive, fulfilling, work-related state of mind that is characterized by vigor, dedication and absorption." Robinson et al (2004) perceive engagement as one level over commitment and they define employee engagement as detailed by Bedarkar, M. \& Pandita (2014) that employee engagement as "a positive attitude of employees towards their organizations and its values, wherein employees have awareness of business context and work to improve job and organizational effectiveness." Then, by focusing on the organizational perspective, Bedarkar, M. \& Pandita (2014) presents what Fleming and Asplund (2007) define that employee engagement as "the ability to capture the heads, hearts, and souls of your employees to instill an intrinsic desire and passion for excellence." In this case, they also explain that engaged employees are those who want the organization to be successful because they are emotionally, socially, and spiritually connected to the mission, vision, and objectives of the organization. Marcey \& Schneider (2008) also define engagement as "discretionary efforts" and/or "extra role effort of behavior" done by the employees beyond the required work tasks. The engaged employees, according to them, are those who are eager to do more and much more for the organization, and keep trying to do the best what the beyond.

Kumar \& Swetha (2011) said that most of definitions of employee engagement are focused on meaning that employee engagement as "emotional and intellectual commitment to the organization." Employee engagement is also said to be "passion for work" (Truss et al, 2006) considered as a psychological state. It is "the individual's involvement and satisfaction with as well as enthusiasm for work" (Harter, Schmidt \& Hayes, 2002). In the level of practice, it is measured "how each individual employee connects with your company and how each individual employee connects with your customers" (Lucey, Bateman, \& Hines, 2005).

\subsection{Drivers of Employee Engagement}

The term 'driver' in this context is understood as defined by Ahlowalia et al (2014) that "a driver is something that drives or leads or results to a particular phenomenon." Employee engagement itself is a specific term in human resource development and management field with a number of factors which can drive it because employee engagement is something really wanted and needed for the future prospect of organization. It needs to be struggled. Therefore, the other primary part which interests the researchers is the driver which leading the employees to be engaged. Many drivers of employee engagement recommended by the researchers to do but 
there is no one of them is claimed to be the most effective one. It is due to the contextual considerations or various working environment. The drivers of engagement from researchers can be discussed here.

Hewitt Associate (2004) formulates a model of employee engagement in which the drivers of engagement covers eight components such as 1) work (intrinsic motivation, work tasks, resources), 2) people (coworkers, manager, senior leadership), 3) opportunities (recognition, career opportunities), 4) compensation (pay, benefits), 5) procedures (policies, human resource), and 6) quality of life (physical work environment, work/life balance, safety). The factors above should be provided by the organization in order to get engaged employees. The better the factors are met accordance with the employees' needs the more engaged the employees in accomplishing the work tasks for better performance.

Robinson et al (2004) as cited by Ahlowalia et al (2014) stated that a sense of feeling valued and involved is acknowledged to be the strongest driver of employee engagement such sense of feeling is driven by a number of factors such as 1) training, development, and career, 2) immediate management, 3) performance and appraisal, 4) communication, 5) equal opportunities and fair treatment, 6) pay and benefits, 7) health and safety, 8) cooperation, 9) family friendliness, and 10) job satisfaction.

Some results of study describing the drivers of engagement have been concluded by Pandita (2014) that the researchers find various factors which drives employee engagement. Mani (2011) predicted four drivers, such as employee welfare, empowerment, employee growth and interpersonal relationships. Seijit (2006) found the $10 \mathrm{Cs}$ of employee engagement., such as connect, career, clarity, convey, congratulate, contribute, control, collaboration, credibility and confidence. A study by IES (2004) identified a number of drivers of employee engagement, namely job satisfaction, feeling valued and involved, equal opportunity, health and safety, length of service, communication and cooperation. Moreover, the early stage of enhancing employee engagement should be done by considering a number of drivers identified by Shilpa (2013), namely employee branding, recruitment, job design, employee selection, training and development, compensation, performance appraisal, retirement.

In accordance with the hierarchical model of engagement factors, Penna (2007) as cited by Ahlowalia et al (2014) proposes a model which is relatively similar with Maslow's need hierarchy model of motivation. The model says that the bottom level is basic needs of pay and financial benefits. After being satisfied with these needs, the employee needs to get self-development and learning opportunities, in which training and education should be provided. The next level is the opportunity for promotion, and finally the effective leadership style which encourages the employees to reach their maximum potential. Then, when all of the levels have been stepped, they are eager to reach the highest level which is called 'meaning at work'.

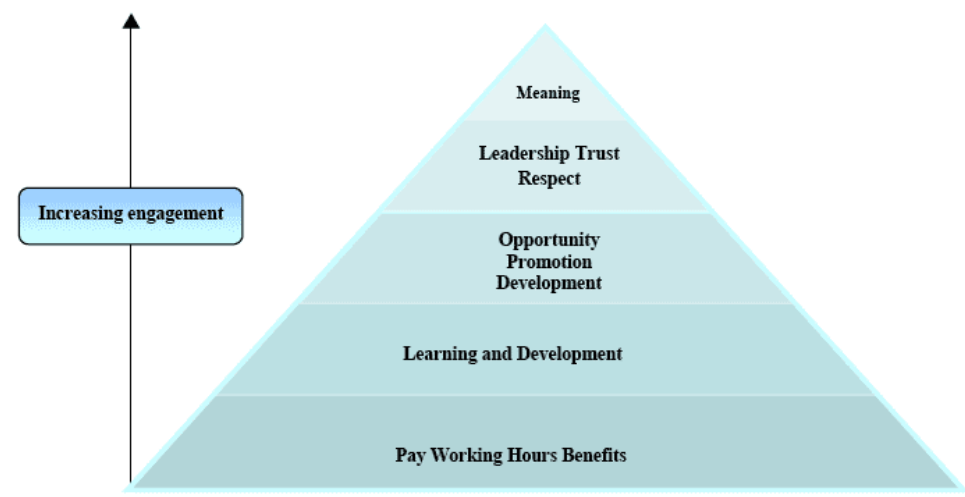

Increasing Hierarchy of Employee Engagement

Source: Penna(2007)as cited by Ahlowalia et al (2014)

\subsection{Definition}

\section{Counterproductive Work Behavior}

Deviant practices done by employees within organization are included to be behavioral aspects mostly found due to various causes and consequences of management practices. Such deviant behavior is negative and harmful for the organization and its members that is lately named counterproductive work behavior (CWB). It is turning to be a popular concept in the field of human resource management and development and defined in various versions by both academician and human resource consultants and managements. An F., and Wang, B. (2016) perceive CWB is "one of the negative responses of employees to the abusive supervision." It is different from Kelloway et al (2010) that perceive CWB as "a form of protest behavior in which individuals and groups attempt to redress, draw attention to, or express dissatisfaction with organizational events." CWB is also viewed as 'willful behaviors' performed by employees that harm both the organization and its members (Spector \& Fox, 2005). Anjum \& Parvez (2013) define CWB as a set of negative 
and destructive behaviors to the organization exerted by the employees by disturbing its operation and assets or hurting coworkers in such a way which in turn makes inefficiency. Fox et al (2001) also define CWB as a behavior intended to have a detrimental effect on the organization and its members. According to Robinson \& Bennett (1995) as cited by Piskin et al (2014) that CWB is "a voluntary behavior that violates significant organizational norms and in so doing threatens the well-being of an organization, its members, or both." The other view on OCB is done by Kwok, Au \& Ho (2005) as cited by Joe-Akunne et al ((2014) that CWB is an 'occupational crime' which may lead to severity starting from the minor acts, namely embarrassing co-workers and leaving early until any serious acts, like sabotage and theft.

\subsection{Dimensions of Counterproductive Work Behavior}

CWB as a deviant behavior destructive and/or harmful to the organization and its members has many dimensions of acts identified by scholars based on their research results. It has two targets, namely the organization and the members. The destructive behaviors performed by the employees extends till the danger level or severity starting from minor acts like talking back coworkers or embarrassing them , leaving work early, coming late until the dangerous acts like sabotage, theft, etc. Certainly, CWB is unwanted or unexpected

The dimensions of CWB identified by researchers categorized as CWB directed to the organization are intentionally making mistakes, wasting time and money, decreasing productivity, disobeying orders, even stealing from the company, and that directed to the members of organization is hindering other colleagues (An F., and Wang, B. (2016). Spector et al (2006) as cited by Krischer et al (2010) proposed five categories of CWB, namely 1) abuse to coworkers, for example, ignoring or arguing with coworkers, 2) sabotage, for example, intentionally and physically destroying organization's property), 3) theft, 4) production deviance, for example, intentionally working slowly, intentionally make mistakes, or neglecting to follow procedures), and 5) withdrawal, for example, taking longer breaks than allowed, arriving late, leaving early). The first component is directed to the members of organization. Anjum \& Parvez (2013) also explaining the dimensions of CWB gathered from many researchers covering absenteeism, spreading of nasty rumors, sabotage, verbal abuse, theft, physical assault, stealing from coworkers, or coming late to workplace, lying, refusing to cooperate, physical assault, withdrawal, and withholding of efforts.

Some phenomena such as theft, property destruction, misuse of information, unsafe behavior, poor attendance, and poor quality work are dimensions of counterproductive work behavior (Idiakheua, \& Obetoh, 2012). Also, an act can be a workplace deviance if it violates the major rules of organizational life (Spector \& Fox, 2005). This includes absenteeism, abusing sick day privileges, abusing drugs and alcohol, filing fake accident claims, sabotaging, breaking organizations' rules, withholding effort, stealing, taking long breaks, working slowly, harassing other employees and hiding needed resources (Abdul,2008). Joe-Akunne et al (2014)

\section{The Role of Employee Engagement in Anticipating CWB}

Employee engagement and counterproductive work behavior have an opposite relation. Increasing another will decrease one another. It means that if employees are getting more engaged, counterproductive work behavior will be much more avoided. The organization is safe from harmful and destructive behaviors as long as employee engagement is well improved and sustainably maintained. On the other hand, the organization is going to be at risk of CWB if its employees are not engaged. The engaged employees have strong physical and psychological involvement that is not easily affected by any factors of CWB, namely injustice or unfairness. The effective strategy of keeping the employees away from CWB is making them more engaged and much more engaged, not only committed. Employee engagement is said to be one ahead of commitment and the committed employees is not as strong as the engaged employees in facing and coping any factors of CWB and save themselves from harmful behaviors any way (Robinson, 2005).

CWB is certainly avoided and should be well anticipated by performing any efforts leading to improving and maintaining the predictors and/or drivers of employee engagement as discussed above. Therefore, related to the CWB avoidance, employee engagement should be well prepared at the early time of hiring. It is because that the wrong people selected by the organization will bring fort new problems and even be a toxic at the next time. Considering importance of employee engagement especially in time of change, it is necessary to realize the roles of employee engagement in anticipating and/or coping CWB that is felt to be harmful for the organization and its members.

The roles of employee engagement may include three facets of improvement. Firstly, employee engagement is the effective strategy to improve performance and keep the employees away from CWB (Bedarkar \& Pandita, 2014; Gruman \& Saks, 2011; Harter et al, 2002); Markos \& Sridevi, 2010; Robertson \& Cooper, 2009; and Saks, 2006). The researchers come to one word that employee engagement has positive effect on performance. The increasing performance shows that the employees are safe from an intentionally wrong act or harmful behavior. Excellent performance pledges the organization to get zero-CWB and such excellent performance is only driven and owned by engaged employees. 
Secondly, employee engagement is the effective way to increase work outcome and/or business outcome (Andrew \& Sofian, 2012; Hanif, et al, 2015; Harter et al, 2002; and Saks, 2006). The best work outcome and/or best business outcome as expected by the organization is only realized and supported by engaged employees. Making them engaged means making best work outcomes and eliminating defects. Intentional mistakes, bad sound of work, worse working communication, and unexpected working condition are found in the quality working environment as created by the engaged employees. The individual, the group, and the organizational goal are surely accomplished due to the extra struggles and discretionary effort performed by the engaged employees. Those lead to the zero defect outcomes which in turn increase the efficiency and the effectiveness as well.

Thirdly, in the frame of future prospect of organization, employee engagement is the key tool of success of an organization (Kallianan \& Adjovu, 2015; P. Roy, 2013). Organizations which operate with deviant practices, harmful behaviors, destructive and demoralized acts are very hard to be successful. Such organizations will not have a good future prospect except being out of business. As a key tool of success, employee engagement drives all elements of production to be powerful, directs the organization on the right track to the bright future, and opens the golden gate leading to the golden future with the golden employees. It was time to be realized that engaged employee is gold which is useful and gives more advantages to the organization all of the time. No words to say that how advantageous the engaged employees are, and how talent the management is.

\section{Conclusion}

Based on the researchers' thought on employee engagement and counterproductive work behavior, this literature study brings fort some conclusions as the following:

Firstly, employee engagement is defined as discretionary and extra effort sincerely, creatively, and rigorously performed by the employee beyond the given work tasks. Researchers propose various drivers of employee engagement in which they come to the similar thought in the primary aspects. The drivers are categorized as managerial facet of engagement and moral facet of engagement. The former refers to factors, namely 1) training, development, and career, 2) immediate management, 3) performance and appraisal, 4) communication, 5) equal opportunities and fair treatment, 6) pay and benefits, 7) health and safety, 8) cooperation, and 9) quality of life. The latter refers to 1) feeling valued and involved, 2) friendliness, and 3) job satisfaction, 4) motivation, 5) leadership trust and respect, 5) meaning.

Secondly, counterproductive work behavior (CWB) is defined as the harmful or destructive behaviors performed by employees as a response or protest to the dissatisfaction or injustice within the organization. In practice level, there is CWB directed to the organization and many is directed to its members (coworkers). The main factor which drives CWB is organizational injustice practices (distributive injustice and procedural injustice). Dimensions of CWB are identified by the researchers with various forms but all of them can be concluded as harmful behavior for the organization and its members as well. Such harmful behavior is also divided into two: verbal attacks or abusive acts such as insulting and non-verbal acts such as sabotage, theft, etc.

Thirdly, the roles of employee engagement in anticipating counterproductive work behavior involves three facets of improvement, namely 1) as the effective strategy in improving performance, 2) as the effective way to increase work outcome and/or business outcome, and 3) in the frame of future prospect of organization, as the key tool of success of an organization. It is also concluded that the law of employee engagement is found that the higher the engagement the lower the counterproductive work behavior the employees perform, or the more engaged the employees the lower the counterproductive work behavior they perform.

\section{Recommendations}

There are two folds of recommendation concerning with the importance of employee engagement to be improved and CWB to be kept away or anticipated. The following are considerable recommendation to be taken account. Firstly, it is recommended to the organization that employee engagement is the best human resource strategy in building a talent human resource management. In this time of change, organizations should focus on managing and developing human resource at the early time of hiring by preparing a well-designed recruitment for engaged employees. Drivers of employee engagement proposed by researchers should be selected and perform under the nature of organization because every organization has a particular tradition and characteristically developed so that particular drivers may be out of the line for a particular organization. It is also recommended that strong foundations, namely job satisfaction and commitment should be built along with the employee engagement program. Highly engaged employees should become a primary focus in any human resource management program because it surely pledges to keep the employees away from counterproductive work behavior (CWB).

Secondly, it is recommended to the further research that some aspects like individual background, family background and socio-cultural background to be investigated whether such backgrounds are influential 
on employee engagement program. Related to gender issues, it is recommended to conduct a study on the different level of engagement between the male and female employees. Moreover, the religious value which is owned by the employees is considerably needed to investigate to look into whether the religiously-devoted employees are more engaged and more capable in coping the counterproductive work behavior (CWB) than those who are not devoted.

\section{References}

[1] Ahlowalia, S., Tiwary, D., \& Jha, A. (2014). Employee Engagement: A Structured Theoretical Review. The International Journal of Business \& Management, 2 (6), 309-317.

[2] An, Feng \& Wang, Bing (2016). Abusive Supervision and Counterproductive Work Behavior: Moderating Effect of Negative Affectivity. Journal of Service Science and Management, 9, 66-73.

[3] Andrew, O. C. \& Sofian, S. (2012). Individual Factors and Work Outcomes of Employee Engagement. Procedia - Social and Behavioral Sciences, 40, 498 - 508.

[4] Anita, R. (2015). Employee Engagement - A Leading Indicator of Employee Retention. International Journal in Management and Social Science, 3 (3), 250-259.

[5] Anjum, M.A. \& Parvez, A. (2013). Counterproductive Behavior at Work: A Comparison of Blue Collar and White Collar Workers. Pakistan Journal of Commerce and Social Sciences, 7 (3), 417- 434.

[6] Ansari, M. E., V. Maleki, S., \& Mazraeh, S. (2013). An Analysis of Factors Affected on Employees' Counterproductive Work Behavior: The Moderating Role of Job Burnout and Engagement. Journal of American Science, 9 (1), 350-359.

[7] Bedarkar, M. \& Pandita, D. (2014). A study on the drivers of employee engagement impacting employee performance. Procedia Social and Behavioral Sciences, 133, $106-115$

[8] Fatima, A., Atif, Q.A., Saqib, A., \& Haider, A. (2012). A Path Model Examining the Relations among Organizational Injustice, Counterproductive Work Behavior and Job Satisfaction. International Journal of Innovation, Management and Technology, 3 (6), 697-701.

[9] Fox, Suzy, Paul E. Spector, P.E., \& Miles, Miles, Don (2001). Counterproductive Work Behavior (CWB) in Response to Job Stressors and Organizational Justice: Some Mediator and Moderator Tests for Autonomy and Emotions. Journal of Vocational Behavior, 59, 291-309.

[10] Gruman, J. A. \& Saks, A. M. (2011). Performance Management and Employee Engagement. Human resource Management Review, $21,123-136$.

[11] Hanif, F., Naqvi1, S. M. M. R., \& Hussain, K. (2015). The Role of Employee Engagement in Work-related Outcomes. Advances in Economics and Business. 3 (6), 204-214.

[12] Harter, J. K., Schmidt, F. L., \& Hayes, T. L. (2002). Business-Unit-Level Relationship between Employee Satisfaction, Employee Engagement, and Business Outcomes: A Meta-Analysis. Journal of Applied Psychology, 87 (2), 268-279.

[13] Heyde, A. V.D., Julia Miebach, M., \& Annette Kluge, A. (2014). Counterproductive Work Behaviour in a Simulated Production Context: An Exploratory Study with Personality Traits As Predictors of Safety-Related Rule Violations. Ergonomics, 4 (2), 1-9.

[14] Joe-Akunne, C. O., Oguegbe, Tochukwu M., Aguanunu, Ralph. (2014). Exploratory Study of Job Insecurity and Entrepreneurial Intention as Correlates of Counterproductive Work Behaviour. International Journal of Academic Research in Business and Social Sciences, 4 (5), 41-52.

[15] Joe-Akunne, C. O., Oguegbe, Tochukwu M., I. Kizito, O. (2015). The Impact of Emotional Intelligence and Job Boredom Proneness on Counterproductive Work Behavior. Advances in Applied Psychology, 1 (2), 101-106.

[16] Kaliannan, M. \& Adjovu, S. N. (2015). Effective Employee Engagement and Organizational Success: A Case Study. Procedia Social and Behavioral Sciences 172 ( 2015 ) $161-168$

[17] Kelloway, E.K., Francis, L., Prosser, M., \& Cameron, James E. (2010). Counterproductive work behavior as protest. Human Resource Management Review, 20,18-25.

[18] Krischer, Mindy M. \& Penney, Lisa M. (2010). Can Counterproductive Work Behaviors Be Productive? CWB as Emotion-Focused Coping. Journal of Occupational Health Psychology, 15 (2), 154-166.

[19] Kumar, D. P. \& Swetha, G. (2011). A Prognostic Examination of Employee Engagement from its Historical Roots. International Journal of Trade, Economics and Finance, 2 (3), 232-241.

[20] Markos, S. \& Sridevi, M. S. (2010). Employee Engagement: The Key to Improving Performance. International Journal of Business and Management, 5, (12), 86-96.

[21] Mensah, M. E., Delle, E., Nmai, B. N. (2015). Ethical Climate as a Predictor of Counterproductive Work Behaviours and Turnover Intention: The Mediating Role of Level of Education. The International Journal of Business \& Management, 3 (8), 305-310.

[22] Meyer, J. P., \& Gagne, M. (2008). Employee Engagement from a Self-Determination Theory Perspective. Industrial and Organizational Psychology, 1, 60-62.

[23] P. Roy, Shilpa (2013). Employee Engagement: Toll for Success of Organization. International Journal of Social Science \& Interdisciplinary Research, 2 (5), 1-8.

[24] Penney, L. M. \& Spector P. E. (2005). Job Stress, Incivility, and Counterproductive Work Behavior (CWB): The Moderating Role of Negative Affectivity. Journal of Organizational Behavior, 26, 777-796.

[25] Piskin, M., Ersoy-Kart, M., Savci, I., Guldu, O. (2014). Counterproductive Work Behavior in Relation to Personality Type and Cognitive Distortion Level in Academics. European Journal of Research on Education, 2(6), 212-217.

[26] Rahim, A. R. A., Shabudin, A., \& Nasurdin, A. M. (2012). Effects of Job Characteristics on Counterproductive Work Behavior Among Production Employees: Malaysian Experience. International Journal of Business and Development Studies, 4, (1), 123145 .

[27] Robertson, I. T. \& Cooper, C. L. (2009). Full engagement: the integration of employee engagement and psychological well-being. Leadership \& Organization Development Journal, 31 (4), 324-336.

[28] Saks, A. M. (2006). Antecedents and Consequences of Employee Engagement. Journal of Managerial Psychology, 21 (7), 600-619.

[29] Sharma, A., \& Thakur, K. (2016). Display of Counter Productive Work Behaviour in Relation to Person-Organization Fit. Global Journal of Human Social Science: Arts \& Humanities - Psychology, 16 (1), 1-9.

[30] Semmer, N. K., Tschan, F., Meier, L. L., Facchin, S., Nicola Jacobshagen, N. (2010). Illegitimate Tasks and Counterproductive Work Behavior. Applied Psychology: An International Review, 59 (1), 70-96.

[31] Swathi, S. (2013). Effecting Employee Engagement Factors. International Journal of Scientific and Research Publications, 3 (8), $1-3$. 